\title{
FIXED ASSETS MANAGEMENT INFORMATION SYSTEM (FAMIS) COLOMBO SOUTH TEACHING HOSPITAL
}

\author{
Dr. Anil Jasinghe*
}

\section{Introduction}

The Colombo South Teaching Hospital is situated amidst a densely populated highly commercialized area in the electorate of Dehiwala Mount Lavinia in western province. The bed strength of the CSTH is 1094 and, it has got two Intensive Care Units, an Accident Service, an Emergency Treatment Unit, seven Operating Theatre Suites, three labour rooms, two Premature Baby Units, thirty five wards and, other ancillary departments. This hospital provides promotive, preventive, curative and rehabilitative services to its service recipients. Other than this, the CSTH provides teaching services and research facilities to undergraduates of Sri Jayawardenepura Medical Faculty and post graduate trainees of the Post Graduate Institute of Medicine. Upgraded to the level of Teaching Hospital in early 90s, it provides the facilities for basic as well as many finer specialties except for several specialties such as cardiothoracic surgery, vascular surgery and, neurosurgery. The Out Patient Department provides services to about 2300 patients per day. On average about 1500 patients attend various clinics held in the hospital daily. Number of patients admitted for in-house care per day is about 400 .

\section{Fixed Assets Management at CSTH in the past}

The hospital has got over forty thousand fixed assets of thousands of kinds all over the premises. Fixed assets are considered to be capital items that can be used over one year. Following are the examples for fixed assets: land, buildings, structures, plant \& machinery, vehicles, surgical equipment, office equipment etc. The fixed assets, depending on the nature of the asset, are to be inventorised in relevant central stores and once issued to a particular unit they have to be entered to the unit inventory. The procurement of items done by the administration and, the procurement subject is handled by a health management assistant. Management of stores is also handled by them. Though a board of survey has to take place at the end of every year to ascertain the assets owned by hospital, this is hardly done. This is because surveying manually managed fixed assets of a large institution such as CSTH is a very cumbersome act and, mobilizing adequate staff is difficult. The entire fixed assets management is done through manual methods. The end result is that the assets of the hospital are not recognized and quantified properly.
As a result of the lack of a proper method of fixed assets management, following are some of the issues that crop up: inability to track the location, quantity, condition, maintenance, depreciation and the current status of an asset, pilferage, wastage, irrational use of capital funds, misdistribution of assets, redundancy of assets, poor preventive and curative maintenance.

\section{Objectives of a Fixed Assets Management Information System}

1. Assets are adequately available for intended purposes.

2. Users have the right quantity of the assets of each type

3. Assets are of right specifications and quality.

4. Assets are well maintained, serviced and are in good operational condition

5. Assets are utilized, as appropriate

6. Users have the ability and right skills to use the requisite assets properly

7. Assets are used only by the authorized officers for official purposes

8. Operational costs of the assets is controlled to achieve optimal results

9. Safety and identified custody of assets.

Fixed Assets Management Information System at CSTH

A fixed Asset Management Information System was installed and commissioned in the hospital in July 2010. The system was developed in the following manner:

1. The software was purchased from an IT solution company.

2. A local area network (LAN) was set up through the funds from Rotary Club of Colombo Regal.

3. A coordinator was appointed to monitor the progress of the fixed assets system.

4. The following staff was trained in the application of the software: health management assistants handling the subjects of maintenance of buildings and machinery, capital item stores, management of vehicles and, Registered Medical Officer handling surgical stores.

5. Every one of the above staff was given a terminal from LAN. The server was installed at the coordinator's desk.

6. Lists of fixed assets with details in all the units in the hospital were gathered using a standard format and entered in to the system. 


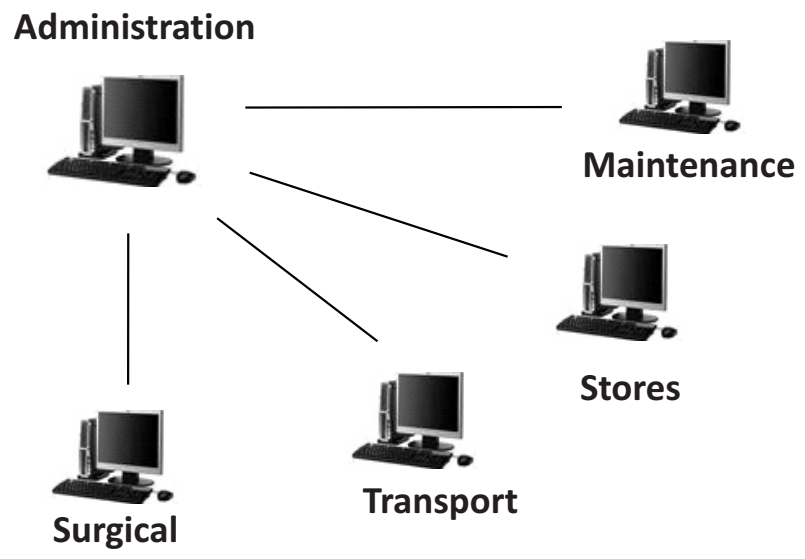

\section{Surgical}

Using this terminal the surgical equipment is managed. Once a new piece of surgical equipment arrives in the surgical stores the item will be entered in the database and issues to wards and other units are made using this terminal. Therefore, the stock position can be easily identified; items issued and transferred details are available. The equipment by type, by brand, by company, by age, by warranty, by service agreements can be made available.

\section{Transport}

The hospital can record all the details of the vehicles belonging to the hospital. Also fuel issuing process can be managed and generate more valuable reports such as,

$$
\begin{aligned}
& \text { * Daily Fuel Issuing Report } \\
& \text { * Monthly Fuel Issuing Report } \\
& \text { * Yearly Fuel Issuing Report }
\end{aligned}
$$

Vehicle maintenance details also can be managed by generating more valuable reports.

\section{Stores}

It is possible to update both general and subsidiary records of store items such as equipment, furniture and machinery. Items can be located at any time very quickly hence minimizing losses and wastage of assets. A unique identification number is assigned and labeled on each and every item preventing any duplication.

\section{Maintenance}

Using this terminal, for example, hospital can manage all aspects of maintenance of machinery and equipment, e.g. air conditioners. Cost effectiveness of repeated repairs of equipment can be decided upon.

\section{Administration}

The Fixed Assets Register (FAR) is the register to track the assets and its usage. FAR must be kept in order to be in compliance with legislation governing departments, corporations and companies. The reporting option that is built in provides reports including assets by category and department, check-in/check-out, net book value of assets, assets past due, audit history and, transactions. The basic details included in a FAR are: Category of asset, Description of asset, Date of purchase, Department, Asset number, Location, Vendor, Invoice number, Invoice date, Valuation method, Method of computation of depreciation, Current value, Scrap value, Life span, and details of use.

Using this terminal management can monitor the information on care and maintenance of fixed assets through the properly kept records hence minimizing the expenditure and can obtain complete details of each custodian and his/her responsible items quickly. By using this information, the supply chain of the hospital could be planned and improved in an ongoing manner.

An example of a report is illustrated in the annexure.

\section{Investment incurred on FAMIS}

1. Setting up of the LAN ----------- SLR 250000.00 (Funded by Rotary Club of Colombo Regal)

2. Purchase of software SLR 150400.00 Total 400400.00

\section{Benefits of the FAMIS}

1. Real time fixed asset analysis: availability, quantity, operationability, value, depreciation etc.

2. Planning investment on fixed assets: liaise with the Ministry of Health in obtaining funds in a better realistic manner.

3. Transfer of fixed assets from one unit to another is made easy and transparent.

4. Preventive and curative maintenance of assets can be done in a scientific manner.

5. Expenditure on fixed assets could be found out, planned, monitored and managed.

6. Annual board of survey is made easy.

7. Identified custody of assets: only authorized officers can use assets.

\section{Constraints}

1. Inadequate initiative on the part of policy planners.

2. Inadequate exposure of the staff to modern IT. 
3. Lack of integrated Management Information Systems in other related agencies.

4. Potential transfer of staff trained to run the MIS system out of the hospital due to centralized human resource management.

5. Lack of a dedicated staff to look into all aspects of MIS.

6. Lack of proper operational guidance for users of assets.

7. Inadequate attention paid to budgeting for servicing, maintenance, supplies and repairs of assets.

\section{Conclusion}

The Management Information Systems (MIS) is a key requirement in any organization that work towards delivery of quality services to the stake holders. The public sector organizations are no exceptions in this regards especially in light of the globalization, competition, liberalized economies and fast changing environmental conditions. Therefore, the strategic management practices must be applied in all public sector organizations if they are to make use of scarce resources for managing development programmes and projects for the benefit of the citizens. The MIS plays a significantly important role in effective and efficient decision making.

Annexure

Annual Department Survey of Government Property ( F. R. 858)

Tr. \& Aud. : 66

$2 / 7 / 2011$

Department: Colombo South Teaching Hospital - Colombo South Teaching Hospital - A.O.OFFICE 1

\begin{tabular}{|c|c|c|c|c|c|c|}
\hline ARTICLES & $\begin{array}{l}\text { Section and } \\
\text { Number }\end{array}$ & $\begin{array}{c}\text { Balance } \\
\text { as shown } \\
\text { Per Ledger }\end{array}$ & \begin{tabular}{|c|} 
Accual \\
Balance \\
on Hand \\
\end{tabular} & Surplus & Deficiency & Remarks \\
\hline AIR CONDITION PLANT & $\mathrm{H} 588$ & 1 & & & & \\
\hline ARM CHAIRS STEEL & $\mathrm{F} 296$ & 5 & & & & \\
\hline CHAIRS EASY LONG ARM & $\mathrm{F} 80$ & 1 & & & & \\
\hline CHAIRS REVOLING & F86 & 1 & & & & \\
\hline FILE CABINET (STEEL-4 DRAWES) & $\mathrm{F} 262$ & 1 & & & & \\
\hline HOSPITAL CAPBOARD WITH STAND ( & $\mathrm{F} 238$ & 1 & & & & \\
\hline PLASTIC BASKET $23 \mathrm{~L}$ & $\mathrm{H} 790$ & 1 & & & & \\
\hline STEEL CUPBOARD $\theta^{\prime}$ & $\mathrm{F} 265$ & 1 & & & & \\
\hline TABLE EXECUTIVE (WOODEN) $5 \times 3$ & $\mathrm{~F} 363$ & 1 & & & & \\
\hline TABLE PEDESTEL STAFF OFFCERS & F171 & 1 & & & & \\
\hline TEAPOY LARGE & F191 & 1 & & & & \\
\hline
\end{tabular}

Signatures of members of the Board of Survey 